Article

\title{
Research on the Critical Issues for Power Battery Reusing of New Energy Vehicles in China
}

\author{
Zongwei Liu ${ }^{1,2,3}$, Xinglong Liu ${ }^{1,2}$, Han Hao ${ }^{1,2,4} \oplus$, Fuquan Zhao ${ }^{1,2, *}$, Amer Ahmad Amer 5 \\ and Hassan Babiker 5 \\ 1 State Key Laboratory of Automotive Safety and Energy, Tsinghua University, Beijing 100084, China; \\ liuzongwei@tsinghua.edu.cn (Z.L.); 1xl19@mails.tsinghua.edu.cn (X.L.); hao@tsinghua.edu.cn (H.H.) \\ 2 Tsinghua Automotive Strategy Research Institute, Tsinghua University, Beijing 100084, China \\ 3 Sloan Automotive Laboratory, Massachusetts Institute of Technology, Cambridge, MA 02139, USA \\ 4 China Automotive Energy Research Center, Tsinghua University, Beijing 100084, China \\ 5 Research and Development Center, Saudi Aramco, Dhahran 31311, Saudi Arabia; \\ amer.amer.4@aramco.com (A.A.A.); hassan.babiker@aramco.com (H.B.) \\ * Correspondence: zhaofuquan@tsinghua.edu.cn
}

Received: 15 March 2020; Accepted: 7 April 2020; Published: 14 April 2020

\begin{abstract}
With the rapid development of new energy vehicles (NEVs) industry in China, the reusing of retired power batteries is becoming increasingly urgent. In this paper, the critical issues for power batteries reusing in China are systematically studied. First, the strategic value of power batteries reusing, and the main modes of battery reusing are analyzed. Second, the economic benefit models of power batteries echelon utilization and recycling are constructed. Finally, the economic benefits of lithium iron phosphate (LIP) battery and ternary lithium (TL) battery under different reusing modes are analyzed based on the economic benefit models. The results show that when the industrial chain is fully coordinated, LIP battery echelon utilization is profitable based on a reasonable scenario scheme. However, the multi-level echelon utilization is only practical under an ideal scenario, and more attention should be paid to the first level echelon utilization. Besides, the performance matching of different types of batteries has a great impact on the echelon utilization income. Thus, considering the huge potentials of China's energy storage market, the design of automobile power batteries in the future should give due consideration to the performance requirements of energy storage batteries. Moreover, the TL battery could only be recycled directly, while the LIP has the feasibility of echelon utilization at present. At the same time, it will strengthen the cost advantage of the LIP battery, which deserves special attention.
\end{abstract}

Keywords: new energy vehicle; power battery; battery reusing; echelon utilization; battery recycling

\section{Introduction}

With the continuous support of the government, the number of NEVs (new energy vehicles) has been increasing rapidly in China, which has led to the rapid development of the power battery industry [1-3]. As shown in Figure 1, the installed capacity of China's traction battery is already very large. There was an increase of more than $60 \mathrm{GWh}$ in 2019 and an accumulated installed capacity of more than $205 \mathrm{GWh}$, which is still growing rapidly [4,5]. At the same time, more and more power batteries are approaching the state of retirement with the passage of time. There are two reasons that the scale of batteries to be retired is further increased. First, the service life of power batteries is usually lower than that of the vehicles resulting that a large number of retired batteries will appear before the vehicles are scrapped. Second, the technical level of early NEV products is relatively low; the service life of many power batteries is far shorter than the newly developed batteries. Therefore, it can be 
expected that China will soon usher in the peak period of the retirement of NEV power batteries [6]. Obviously, it will bring serious environmental and security risks if these retired batteries cannot be effectively recycled and managed [7].

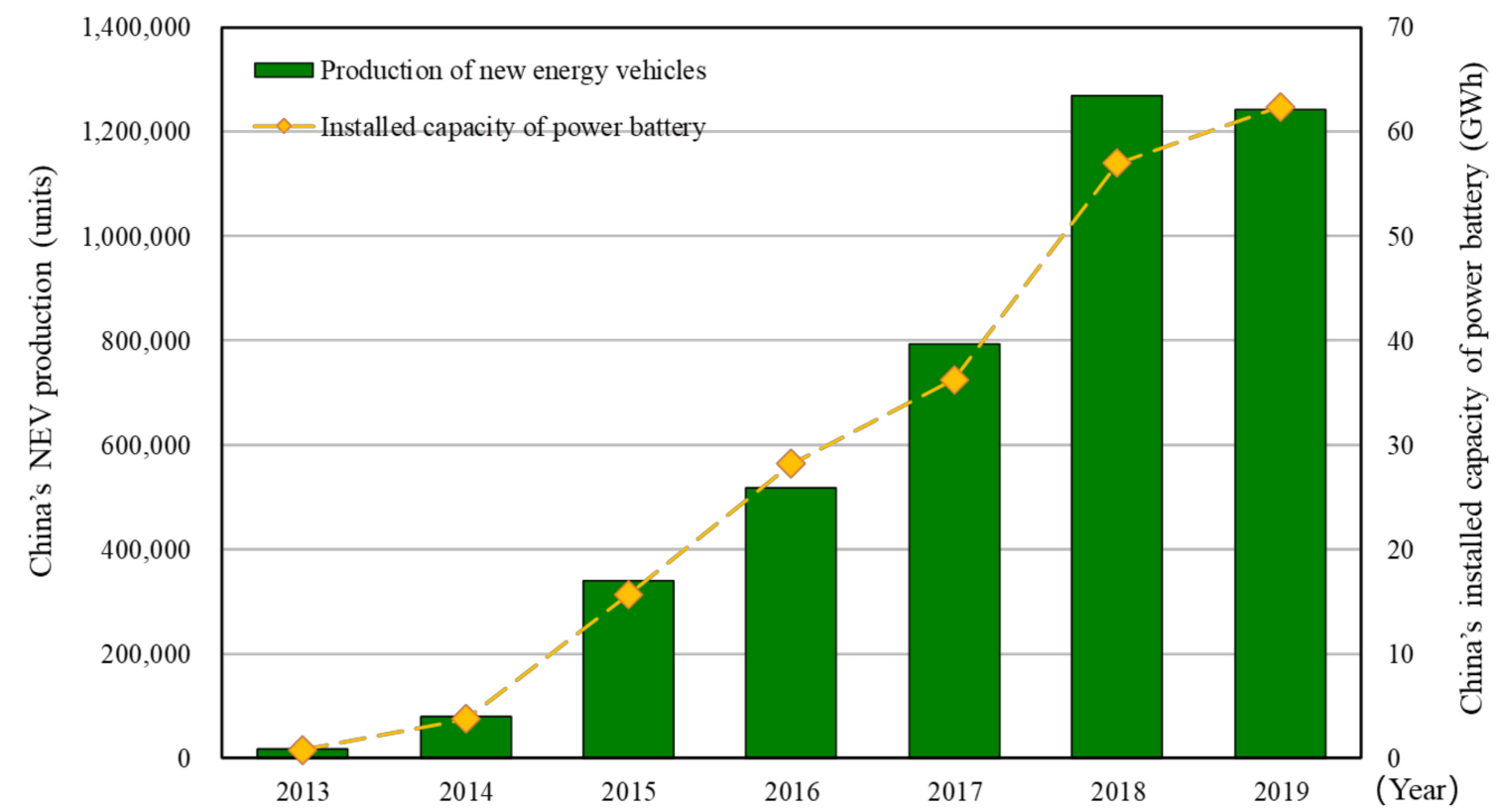

Figure 1. Production of new NEVs (new energy vehicles) and installed capacity of power batteries in China (2013-2019).

For this reason, the Chinese government is stepping up the development of relevant policies on the reusing of power batteries. As shown in Figure 2, the frequency and content of recent relevant policies are getting higher and higher [8,9]. All kinds of signs indicate that China will issue regulations and policies on the mandatory recycling of retired power batteries soon. Thus, it would require enterprises to solve the problem of retired power batteries in the form of laws so as to ensure the sustainable development of the new energy automobile industry. According to the principle of the "Extended Producer Responsibility System", power battery reusing will become the responsibility of vehicle enterprises. The vehicle enterprises will definitely decompose the responsibility along the supply chain, so the whole power battery industry will be affected [10]. Therefore, relevant enterprises need to think ahead, lay out, and prepare in advance to meet the requirements of national laws and regulations.

In fact, the power battery of NEVs contains a large number of metal materials, such as lithium, cobalt, nickel, etc. Its reusing is not only a matter of legal responsibility but also affects the supply status of these metals directly [11,12]. So, it may change the trend of the price of power battery, and then affect the development trend of the industry and the income of enterprises significantly.

For this reason, this paper systematically studies the key issues for NEV power battery reusing in China, including the strategic value, main reusing modes, echelon utilization value, recycling value, and overall value analysis of power battery reusing. 


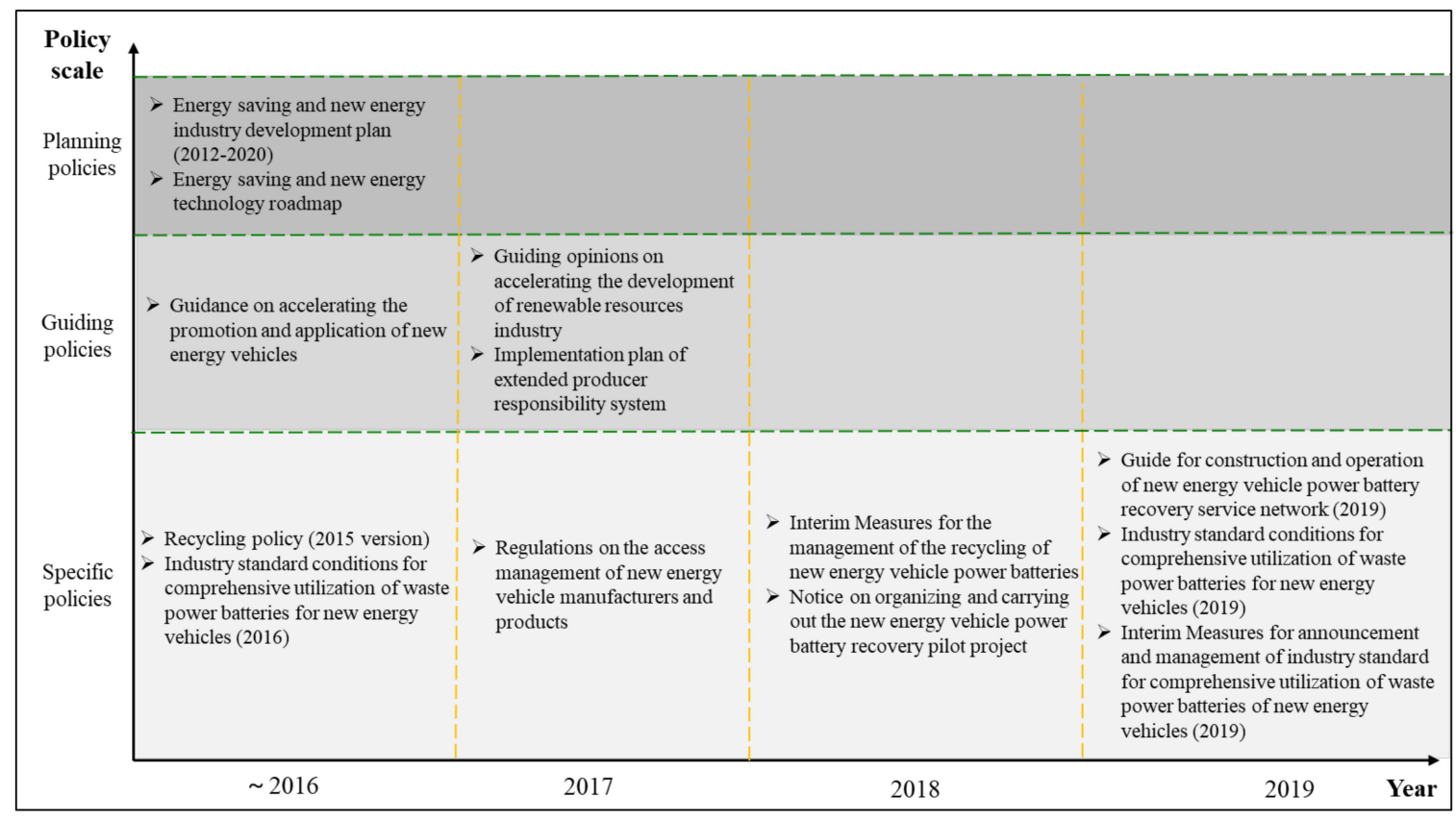

Figure 2. List of relevant policies for power battery reusing in China.

\section{Strategic Value of Power Battery Reusing}

As mentioned above, the retired volume of power batteries for NEVs will be huge and grow rapidly in China. Reusing these batteries has three important strategic values [13].

First, it could solve the environmental pollution and potential safety problems caused by retired power batteries [14]. Based on the historical data of China's NEVs and their power batteries, this paper makes a quantitative estimation of the scale of retired power batteries in the next six years. The evaluation method is shown in Equation (1):

$$
R_{M}=\sum_{M-A}^{M-B} \frac{R_{k}}{A-B+1} \cdot I_{k}
$$

where the $k$ is the year; $R_{M}$ indicates the retirement volume in year $\mathrm{M} ; A / B$ indicates the up/down year of retired power battery life; $I_{k}$ represents the conversion coefficient of influencing factors in the year $k$, which is related to market size, battery type, battery life and installed capacity of batteries [15].

The results of this estimation are shown in Figure 3. It is estimated that the retired volume of power batteries in China will reach about 27 GWh in 2020 and 146 GWh in 2025. It will become a serious threat to the ecological environment. To be specific, it will result in water, soil, and air pollution, as well as public security risks such as short-circuit combustion if the retired power battery with such a huge scale cannot be reused and recycled effectively [16].

Second, it could realize the recycle and reuse of metal resources and reduce the supply risk of power battery raw materials [17]. On the one hand, the demand for lithium, cobalt, nickel, etc. for NEV power batteries is growing. For example, China's power battery industry consumed about 11,000 tons of lithium, 41,000 tons of nickel, and 17,000 tons of cobalt in 2018 [15]. At the same time, China's external dependence on these three metal materials is more than $80 \%$, especially for cobalt, with the overseas import volume as high as $97 \%$ [15]. In this case, the recycling of these metal materials must be realized through the reusing of retired power batteries so as to avoid resource bottlenecks and ensure the safety and control of the industry [18]. 


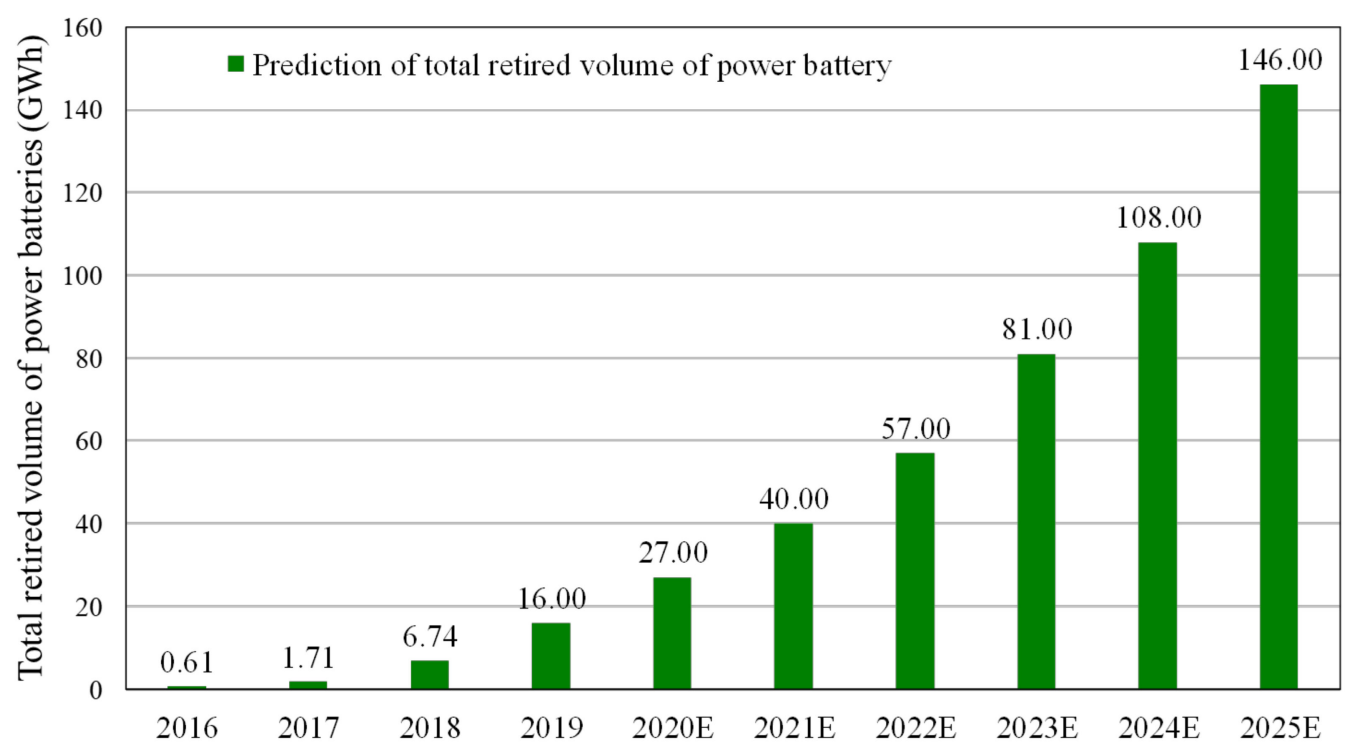

Figure 3. The total retired volume of the new energy vehicle power battery in China.

On the other hand, the current price of power battery is still relatively expensive, which is the fundamental reason why NEVs are at a price disadvantage compared with traditional internal combustion engine vehicles (ICEVs) [19]. As China's subsidy policy for NEVs will be completely phased out after 2020, the NEVs will be mostly market-driven. Therefore, to improve the competitiveness of the NEVs, their cost-performance needs to approach the level of ICEVs without subsidies. The expectation of this industry is that the scale effect will make the price of power battery drop rapidly with the increase of NEVs. However, if a large number of retired power batteries cannot be reused, it is likely that the supply of metal materials would be a bottleneck. It will lead to the price of power batteries rising instead of falling, resulting in a higher cost of the NEVs [14]. In this regard, the reusing of power battery is one of the important factors affecting the sustainable development of China's NEVs industry in the future.

Third, it has the potential to reduce the cost of power battery in automobile enterprises and generate additional social value [16]. The retired power battery should not only simply be dismantled and recycled and the reusing for raw materials. If its potential value can be fully exploited before dismantling and recycling, the retired power battery can be utilized to the maximum extent. Thus, the use cost of the power battery will be effectively shared at different utilization stages [20]. In this case, the recovery and utilization of power battery may not be a burden for the automotive enterprise, and may even bring some profits to the enterprise instead. As a result, it would promote the cost reduction of new NEV products further, and thus constitute a competitive advantage for the enterprise. At the same time, the field of application of retired power batteries is also expected to benefit from waste utilization [21,22]. For the whole society, this means the upgrading of the efficiency of social resources utilization. Therefore, it would also produce certain social values.

It can be seen that China's subsidies for NEVs are about to be phased out entirely. Hence, the industry must attach great importance and study how to maximize the benefits of the reusing of retired power batteries seriously under the situation. This strategically important for the sustainable development of China's NEV industry as well as the construction and improvement of a green energy-saving society in the future.

\section{Main Modes of Power Battery Reusing}

Firstly, the concept of power battery reusing is defined, as shown in Figure 4. 


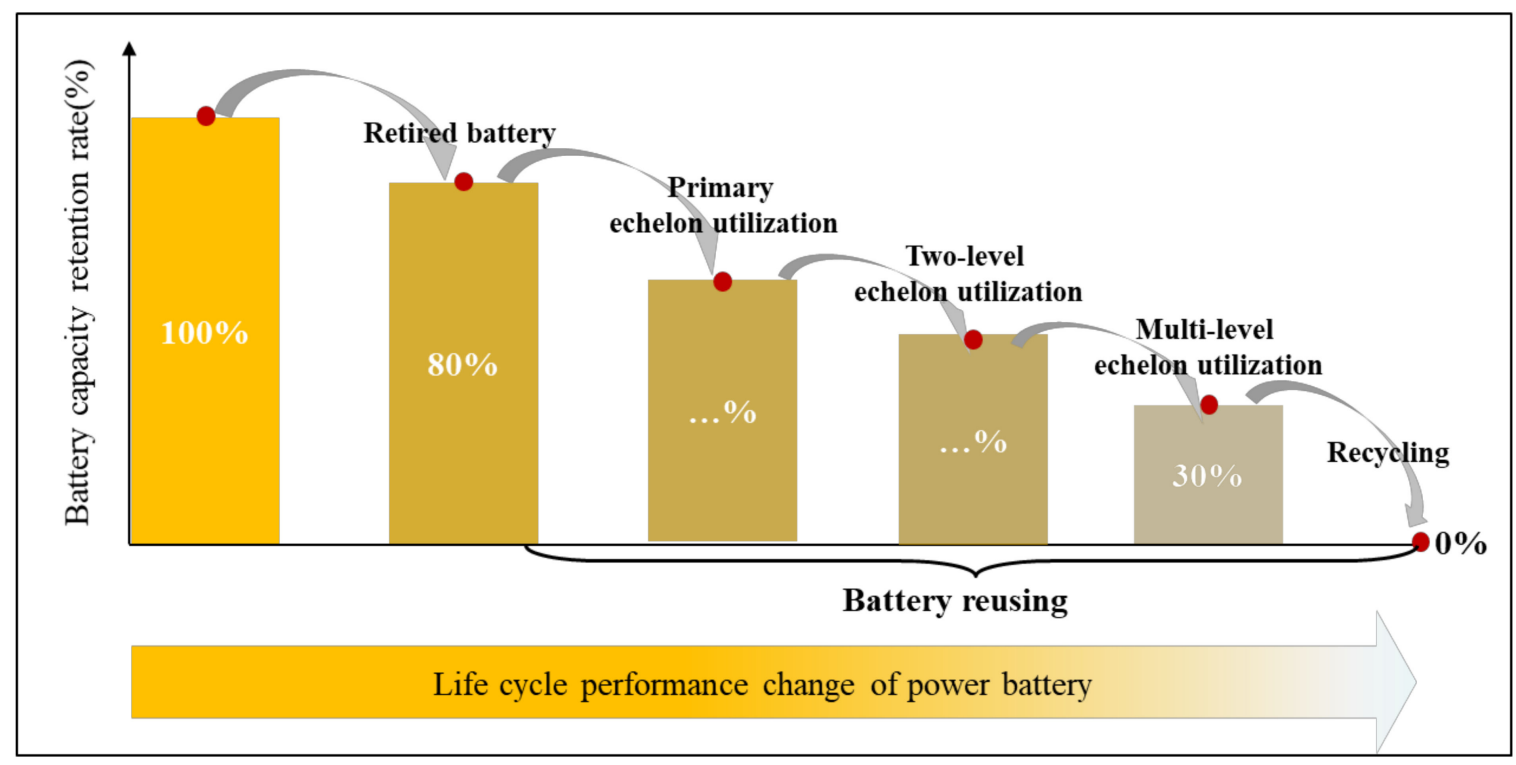

Figure 4. Main ways of power battery reusing of NEVs.

Retired battery: when the performance of the power battery has declined to a certain extent, it needs to be retired from use and then enter the reusing process. For NEVs, the indicator is that the battery capacity retention rate decays below $80 \%$ [23].

Echelon utilization: the batteries retired from the original products can be used in other applications with relatively low requirements on battery performance [24-27]. Theoretically, this kind of secondary utilization can be performed many times, which is the so-called multi-level echelon utilization. NEVs have high requirements for batteries, but the power batteries could be used in micro electric vehicles, communication base stations, energy storage [28], and other fields until the battery capacity retention rate is reduced to $30 \%$ [28].

Recycling: the power battery is dismantled and recycled, which is the last link of reusing [29]. From the legal point of view, it will meet the requirements if the retired battery is recycled. However, the retired battery cannot achieve the maximum benefit when dismantled and recycled directly from the perspective of enterprise management.

Reusing: This is actually a big concept, including two aspects of echelon utilization and recycling. It covers the whole process of processing and processing retired batteries with the basic goal of environmental protection and resource reuse $[13,30]$.

According to the above definition, the reusing of retired power batteries of NEVs could be divided into two main modes, as shown in Figure 5. The first mode is to recycle retired batteries directly, that is, to realize resource recovery and meet regulatory requirements [7]. Mode II is to select a suitable scenario for the echelon utilization of retired batteries to give full play to the residual capacity and then implement the recycling [23]. Obviously, Mode II can obtain greater returns than Mode I in theory, but the actual situation is far more complex than the theory [31]. There are many factors influencing the benefit of echelon utilization, including appropriate echelon utilization scenarios; therefore, there are key technologies, and costs of detecting battery residual energy and regrouping, cooperation modes of all parties involved in echelon utilization, etc. Thus, the specific value of echelon utilization needs to be systematically evaluated to obtain a greater return from the reusing of retired power batteries. 


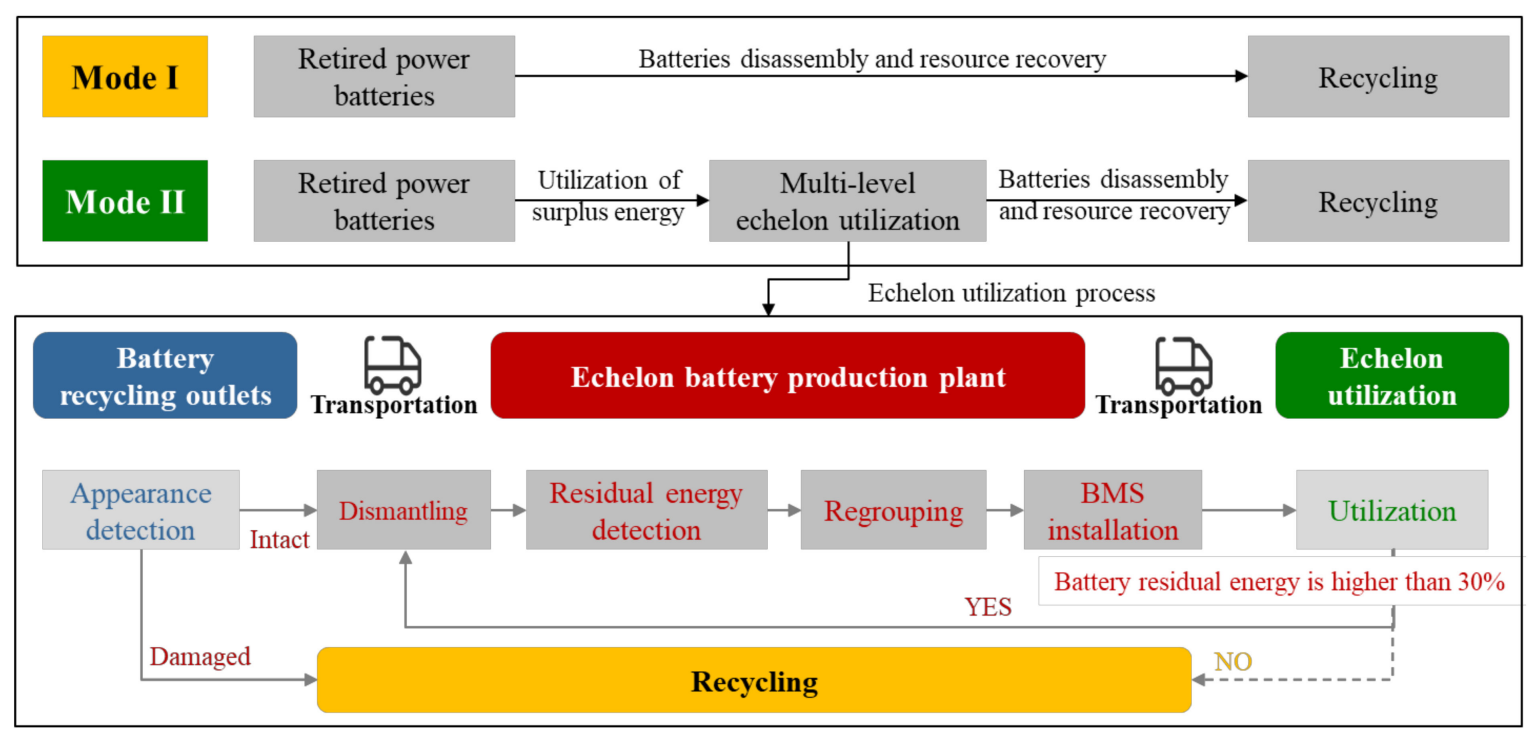

Figure 5. Main reusing modes and the echelon utilization process of retired power battery.

\section{Research on the Key Issues of Power Battery Echelon Utilization}

At present, the mainstream power batteries are TL batteries and LIP batteries. The mass-energy density of the TL battery is higher, which plays a leading role in passenger cars, but its cost is higher than that of the LIP battery [32]. However, the LIP battery exhibits better thermal stability, lower cost, and lower volume energy density. It is more widely used in commercial vehicles [33]. Overall, they have their own advantages and disadvantages and are widely used in NEVs. By the end of 2018, LIP battery accounted for $54 \%$, and TL battery accounted for $42 \%$ of the total installed of NEV power batteries in China [34].

However, there are technical bottlenecks in TL battery when facing echelon utilization. On the one hand, the safety of the TL battery is poor due to the low thermal runaway temperature $\left(180^{\circ} \mathrm{C}\right)$, meaning it is more prone to cause fire and explosion. On the other hand, more nickel is used in the cathode material of the TL battery in order to pursue higher energy density, which results in shorter cycle life of TL batteries [35]. The solution to these problems needs a corresponding technological breakthrough and high costs. So, it is difficult to implement the TL battery echelon utilization at the current technical level. Instead, direct recycling for TL battery is a more reasonable choice. Therefore, this paper only studies the echelon utilization of LIP battery [36].

\subsection{Scenario Selection of Power Battery Echelon Utilization}

There are three important factors to consider when selecting echelon utilization scenarios, including demand matching, utilization cost, and scale capacity. First of all, the performance of retired power batteries must meet the basic needs of echelon utilization scenarios. It includes service life, charging and discharging speed, internal resistance, and working voltage, etc. Secondly, the retired power battery can be used for echelon utilization only after being tested and regrouped. The cost must be low enough to ensure the economy of echelon utilization. Therefore, the technical requirements for batteries in relevant scenarios could not be too high. Finally, the ideal echelon utilization scenario should have a large and stable battery demand due to the number of retired power batteries increasing year by year. Otherwise, it cannot play a great role even if the demand matches, and the cost is controllable.

Based on the above three factors, this study conducts a comprehensive analysis of various possible echelon utilization scenarios, and finally extracts the six most likely scenarios $[23,25,37]$. They are divided into two categories: power battery and energy storage battery. The former includes a microelectric vehicle (MEV), electric special vehicle (ESV) (such as sightseeing vehicle, ferry car, etc.), and electric bike (E-Bike). While the latter includes communication base station (CBS), renewable 
energy power station (REPS), and parallel micro-grid (PMG). Each of these scenarios has different battery use characteristics, presented in detail in Table 1.

Table 1. The most likely echelon utilization scenarios and their battery use characteristics.

\begin{tabular}{ccccccc}
\hline \multirow{2}{*}{ Echelon Utilization Scenarios } & \multicolumn{3}{c}{ Power Battery } & \multicolumn{3}{c}{ Energy Storage Battery } \\
\cline { 2 - 7 } & MEV & ESV & E-Bike & CBS & REPS & PMS \\
\hline Depth of discharge & $80 \%$ & $80 \%$ & $100 \%$ & $80 \%$ & $80 \%$ & $80 \%$ \\
Cycle & 450 & 450 & 180 & 600 & 800 & 650 \\
Capacity $(\mathrm{kWh})$ & 13.5 & 13.5 & 1 & - & - & - \\
Current price $(€ / \mathrm{kWh})$ & 65 & 65 & 90 & 31 & 58 & 39 \\
\hline
\end{tabular}

China's low-speed road vehicles, including MEV, ESV, and E-Bike, etc. listed in Table 1, mostly use lead-acid (LA) batteries nowadays. LA batteries have serious environmental pollution problems. At the same time, the energy density, cycle life, and other main indicators are far lower than LIP batteries, as shown in Table 2. But its main advantage is the low cost [38]. With the continuous growth of the power battery scale of NEVs, the retired LIP batteries can be completely used to replace the LA battery. The retired LIP batteries are not only with better performance and lower cost, but also meet the performance requirement is due to the similar power battery application scenario. Therefore, the replacement of LA batteries in low-speed road vehicles should be one of the best scenarios for the echelon utilization of retired power batteries.

Table 2. Performance comparison for different batteries.

\begin{tabular}{cccc}
\hline Performance & LA & LIP & TL \\
\hline Specific energy $(\mathrm{mAh} / \mathrm{g})$ & $40-70$ & $130-165$ & $150-210$ \\
Cycle life (cycle) & $400-800$ & $2000-6000$ & $800-2000$ \\
\hline
\end{tabular}

In addition, China currently has a wide range of demand for energy storage batteries. For example, the renewable energy power stations (photovoltaic power generation, wind power generation, etc.) in Table 1, the microgrid of the distributed independent power sources and communication base stations all have considerable demand for energy storage batteries. With the optimization of China's energy structure and the upgrading of information infrastructure, the demand scale of energy storage batteries will continue to expand. The new production of the energy storage battery to meet the demand will inevitably consume a lot of resources and bear high costs. Therefore, if the retired power battery of NEVs can be used for energy storage, it can not only fully accommodate the increasing number of retired power batteries, but also meet the growing demand for energy storage batteries. This will produce huge social benefits [39]. In fact, the electric vehicle itself is also regarded as a movable energy storage device. The power batteries have already been and will play the role of energy storage to a certain extent before retired.

As mentioned above, the retired battery can be used in a multi-level echelon in theory. That is to say, until the last remaining energy is exhausted, it can be repurposed from one echelon utilization scenario to the next echelon utilization scenario and so on. However, the switching of each echelon utilization scenario will produce certain costs, including battery purchase, detection, regrouping, and transportation, etc. Especially at present, echelon utilization technology is still in development, leading to the high cost of battery detection and regrouping. Thus, too many levels of echelon utilization will lead to high costs and reduce expected profits. So, the multi-level echelon utilization has no realistic possibility under the existing technology level.

For this reason, this paper only studies the echelon utilization scheme of one or two levels. In the two-level echelon utilization scheme, the power battery with a higher matching degree of battery demand is taken as the first level, and the energy storage battery is taken as the second level. Note that 
the use of E-Bike as the first link is not considered because it is relatively scattered, and the single-car battery load is small. Therefore, six primary application schemes and six two-level application schemes are determined as the research objects, as shown in Table 3.

Table 3. Echelon utilization schemes of retired power battery.

\begin{tabular}{|c|c|c|c|c|c|c|c|c|c|c|c|c|}
\hline \multirow{2}{*}{ Echelon Utilization Schemes } & \multicolumn{6}{|c|}{ Primary Echelon Utilization Scheme } & \multicolumn{6}{|c|}{ Two-level Echelon Utilization Scheme } \\
\hline & F-1 & F-2 & F-3 & F-4 & F-5 & F-6 & S-1 & S-2 & S-3 & S-4 & S-5 & S-6 \\
\hline MEV & $X$ & & & & & & $\mathbf{X}$ & $X$ & $X$ & & & \\
\hline ESV & & $X$ & & & & & & & & $X$ & $X$ & $X$ \\
\hline E-Bike & & & $X$ & & & & & & & & & \\
\hline CBS & & & & $X$ & & & $X X$ & & & $X X$ & & \\
\hline REPS & & & & & $X$ & & & $X X$ & & & $\mathbf{X X}$ & \\
\hline PMG & & & & & & $X$ & & & $X X$ & & & $X X$ \\
\hline
\end{tabular}

Note: " $\mathrm{X}$ " represents the first-level echelon utilization; “ $\mathrm{XX}$ " represents the second-level echelon utilization.

\subsection{Economic Benefit Analysis of Power Battery Echelon Utilization}

\subsubsection{Economic Benefit Evaluation Model of Echelon Utilization}

In order to evaluate the economic benefits and influencing factors of different echelon utilization schemes, this paper constructs an evaluation model of echelon utilization economic benefits, as shown in Figure 6. There are two key assumptions in this model. First, this study assumes that there are enterprises with enough technology and capital to complete the corresponding work in each link of echelon utilization. This paper only studies the overall cost and benefit of the whole process from the perspective of the industrial chain. However, as for which specific enterprises complete which link of work, and the benefit distribution of enterprises with different roles is not in the scope of this study. Second, in order to simplify the calculation, the battery capacity retention rate is used to measure the overall performance of the battery and the only judgment condition of battery state of health, service life, and whether it should be transferred to the next link [40,41].

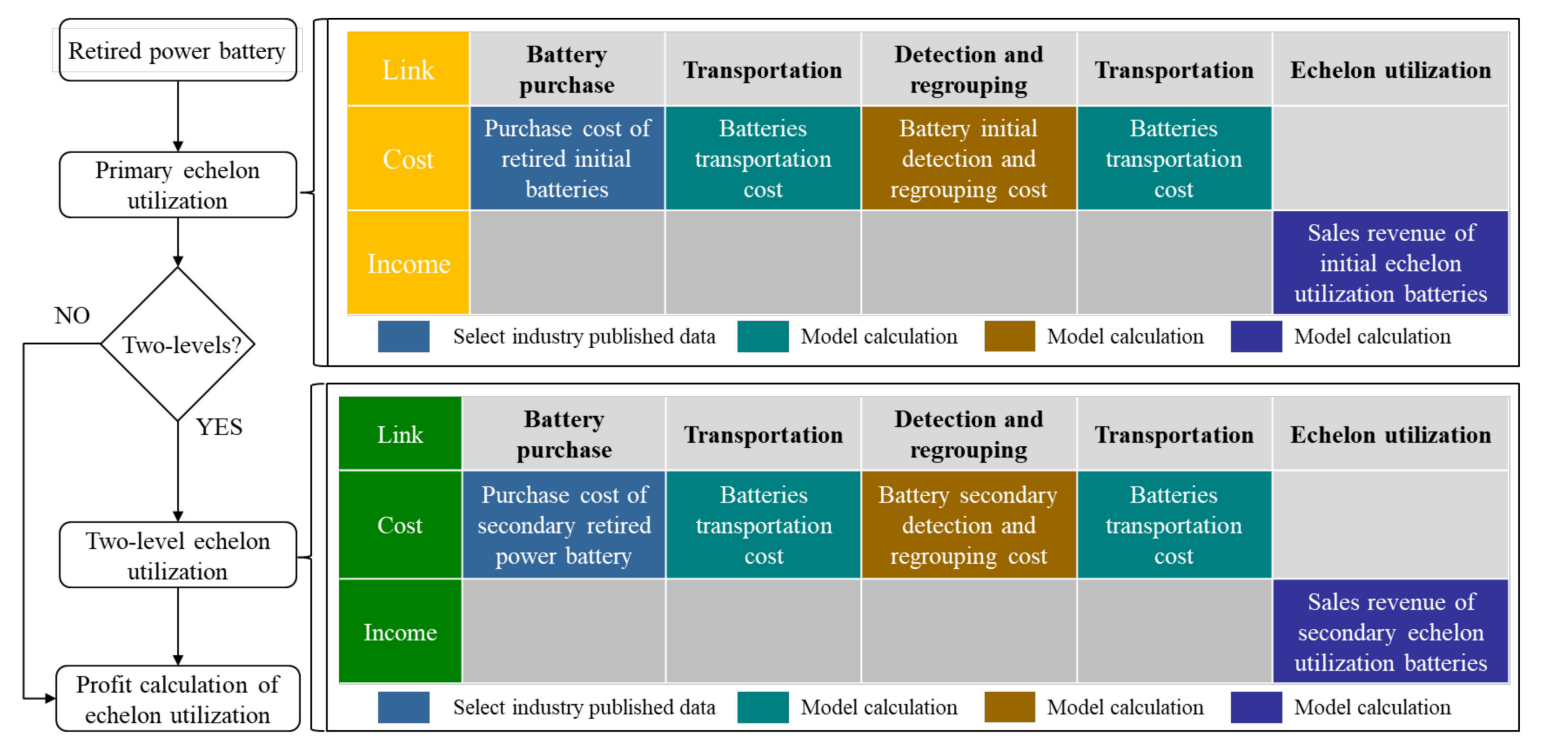

Figure 6. Block diagram of economic benefit evaluation model for the echelon utilization of retired power battery.

The time point of decommissioning of the battery from the whole vehicle and the judgment condition of the ultimate scrapping are all expressed by battery performance; therefore, all expressions 
related to the battery service life are also unified to the form of capacity retention rate in the process of model calculation. The specific definition of the capacity retention rate is shown in Equation (2).

$$
\text { Battery capacity retention rate }=\frac{C_{l}}{C_{\text {new }}}
$$

where the $C_{l}$ represents the battery capacity after $l$ cycles, and $C_{\text {new }}$ indicates the nominal capacity of the new power battery.

With the use of the battery, the capacity retention rate will continue to decline. The capacity decay rate $(\eta)$ of each cycle is defined as the impact of the new charge-discharge cycle on the battery performance. The specific calculation is as follows:

$$
\eta=\frac{C_{l+1}}{C_{l}}
$$

where $C_{l+1}$ indicates the battery capacity after $l+1$ cycle.

According to the study conducted by Schuster, the battery capacity retention rate can be approximately considered constant before the battery performance drop to the capacity diving point [41]. The capacity retention rate can be calculated using the capacity decay rate $(\eta)$ and cycles as follows:

$$
\text { Battery capacity retention rate }=\eta^{l}
$$

And the battery capacity retention rate would be different due to the depth of discharge (DOD) under the use condition. According to the three DOD corresponding to the six application scenarios as abovementioned, different $\eta$ values are used to calculate the life of the echelon utilization battery, as shown in Table 4.

Table 4. Capacity decay rates under different depth of discharge (DOD).

\begin{tabular}{cc}
\hline DOD & Capacity Decay Rate $\eta$ \\
\hline $60 \%$ & $99.98 \%$ \\
$80 \%$ & $99.97 \%$ \\
$100 \%$ & $99.96 \%$ \\
\hline
\end{tabular}

As shown in Figure 6, the costs incurred in the process of echelon utilization mainly include the purchase and transportation costs of retired batteries as well, as the costs of echelon utilization battery detection and regrouping. The revenue comes from battery sales revenue [42]. It should be noted that the cost of each link is different due to the difference in battery performance in primary and secondary echelon utilization. As abovementioned, the echelon utilization profit can be calculated by the total revenue and expenditure, as shown in Equation (5). In order to make the results as broadly applicable as possible, the cost, revenue, and profit are all in term of $€ / \mathrm{kWh}$ in this study. Note that the study converts RMB to Euro at the 2019 exchange rate.

$$
P_{c}=\sum_{i=1}^{N}\left(S R_{e}-C_{p 1}-C_{t r}-C_{r}\right)
$$

where the $P_{c}$ is the profit of echelon utilization; $S R_{e}$ represents the sales revenue of echelon utilization batteries; $C_{p 1}$ indicates the purchase cost of retired batteries; $C_{t r}$ is the batteries transportation cost; $C_{r}$ indicates the cost of battery detection and regrouping.

For the sales revenue of the echelon utilization battery: there are two calculation methods. The first method is based on the residual capacity of the retired LIP battery. It calculates profits according to the 
discount coefficient on the basis of the new battery price [37]. The specific calculation is Equation (6) as follows:

$$
S R_{e}=\frac{P_{\text {new }} \cdot T O_{\text {retired }}}{T O_{\text {new }} \cdot D R}
$$

where the $P_{\text {new }}$ is the price of new LIP battery; $T O_{\text {new }}$ represents a nominal capacity of the LIP battery; $T O_{\text {retired }}$ indicates the capacity of LIP battery after decommissioning; $D R$ is the discount coefficient [37].

The second method is based on the price of the new LA battery and the different cycle life of the two batteries. The specific calculation is Equation (7) as follows:

$$
S R_{e}=\frac{P_{q s} \cdot L_{q s}}{L_{L i}}
$$

where the $P_{q s}$ is the price of the replaced LA battery in the echelon utilization scenario; $L_{q s}$ represents LA battery cycle life; $L_{L i}$ indicates the cycle life of retired LIP power battery.

Finally, the lower one in the calculation results of Equations (6) and (7) is taken as the battery sales price, which is more likely to be accepted by the demander of the echelon utilization scenario, as shown in Equation (8):

$$
S R_{b}=\min \left\{\frac{P_{\text {new }} \cdot T O_{\text {retired }}}{T O_{\text {new }} \cdot D R}, \frac{P_{q s} \cdot L_{q s}}{L_{L i}}\right\}
$$

Purchase cost of retired battery: when the LIP battery is retired from the vehicle, the capacity retention rate is $80 \%$. Its value is taken from the industry average data, about $13.4 € / \mathrm{kWh}$ [10].

Battery transportation cost: in this study, only the use cost of freight cars is included, and the cost of vehicle purchase and depreciation is not considered. In order to minimize the cost, trucks with different carrying capacity will be selected according to different transportation needs. In addition, the transportation process is divided into two types according to the distance, including intercity transportation and trans provincial transportation. In this study, the average distances of the two types of transportation are $50 \mathrm{~km}$ and $500 \mathrm{~km}$, respectively. Most of the echelon utilization scenarios are short-distance intercity transportation. Only when retired batteries are applied to renewable energy power stations and large-scale communication base stations, can long-distance trans provincial transportation be considered [43]. According to the current use of freight in China, the cost of intercity transportation and trans provincial transportation can be calculated, as shown in Equation (9):

$$
\left\{\begin{array}{c}
C_{t}^{\text {intercity }}=0.00052 \cdot D \\
C_{t}^{\text {trans provincial }}=0.000077 \cdot D
\end{array}\right.
$$

where the $C_{t}^{\text {intercity }}$ is the intercity transportation cost; $C_{t}^{\text {trans provincial }}$ represents trans provincial transportation cost; $D$ indicates the transportation distance.

Detection and regrouping cost: as echelon utilization is still in the exploration and preliminary stage, there is no open direct cost data available. Based on the operation cost of the existing battery treatment plant, this study estimates the detection and regrouping cost of the battery through cost apportionment methods. Considering the different technical difficulties of the different echelon utilization scenarios, the scenario correction coefficient is added to modify the echelon utilization calculation model developed by the National Renewable Energy Laboratory (NREL) [43], as shown in Equation (10):

$$
C_{r}=C_{\text {factory }} \cdot C F / Q
$$

where the $C_{\text {factory }}$ is the enterprise detection and regrouping cost of echelon utilization, including fixed asset cost and labor cost; $C F$ represents the correction coefficient of battery detection and group cost in different echelon utilization scenarios which is related to the processing difficulty and time [37]; $Q$ indicates the annual production of echelon battery. 


\subsubsection{Economic Benefit Analysis of Echelon Utilization}

Based on the evaluation model, the benefits of the echelon utilization of various schemes are calculated, and the results are shown in Figure 7. Firstly, it can be seen that most of the schemes of primary and secondary echelon utilization can achieve positive benefits. It shows that if the relevant industrial chain is coordinated, the echelon utilization of retired power battery is profitable. Then the cost of using power battery for BEVs is leveraged by echelon utilization [20]. With the development of battery detecting and regrouping technology, the benefits of echelon utilization are expected to expand in the future further. In addition, only LIP battery has the technical feasibility of echelon utilization, which also means that echelon utilization is expected to further increase the cost advantage of LIP battery comparing to TL battery.

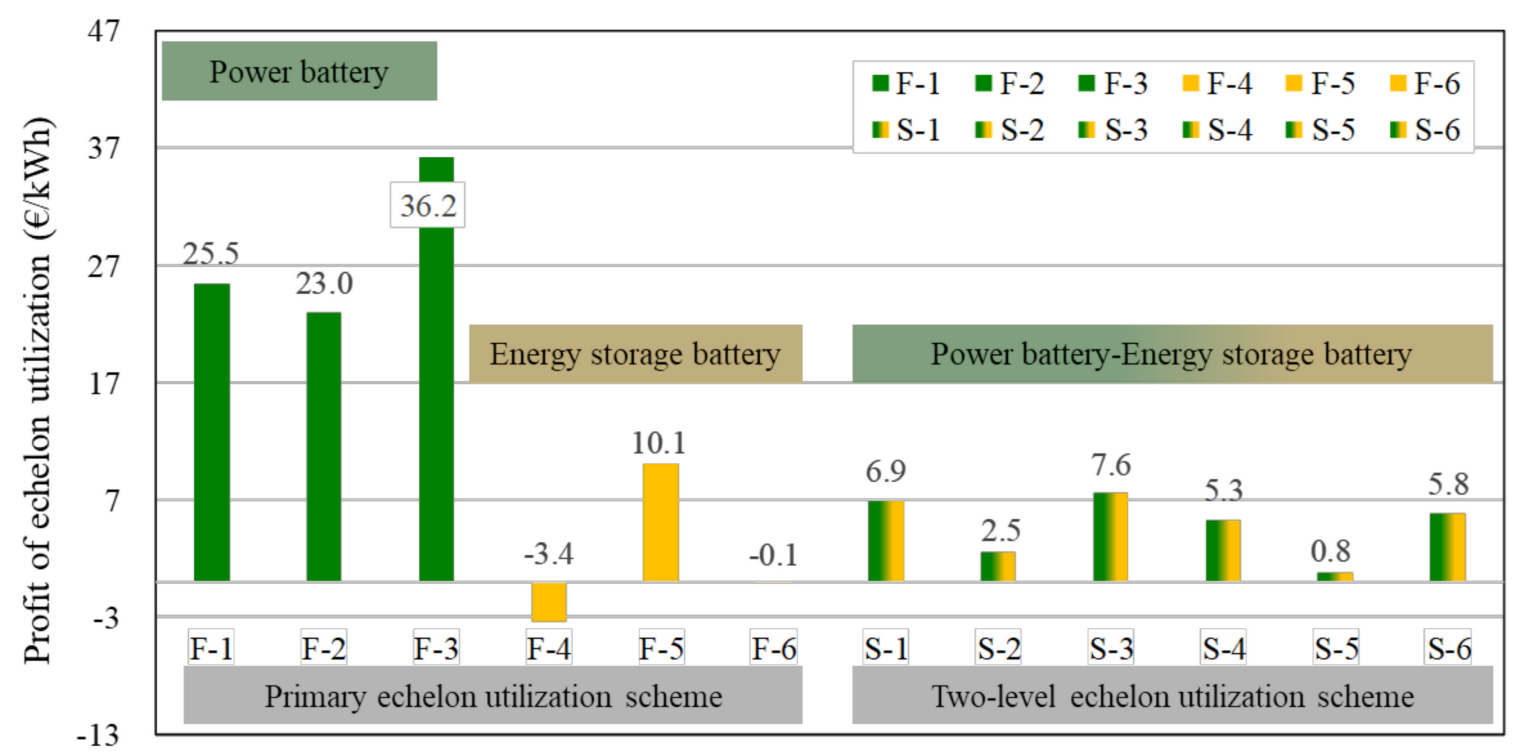

Figure 7. Comparison of economic benefits of the different echelon utilization schemes.

Second, compared with the three scenarios of power battery replacement in the primary scheme, the profits of all the secondary schemes are lower. It can be explained that the increase in echelon utilization levels will lead to the decrease of echelon utilization income. Meanwhile, this shows that it is reasonable to study only the primary and secondary schemes in this paper. In a word, multi-level echelon utilization is only a theoretical concept at present. Hence, more attention should be paid to the development of the first level echelon utilization scheme in industrial practice in the future. Moreover, the two-level scheme should be properly considered according to the urgency of the scene demand.

Third, the performance matching of different batteries has a significant impact on the benefits of echelon utilization. From the analysis of the primary echelon utilization scheme, it can be seen that the echelon utilization scenario based on the power battery for transportation purposes can achieve greater benefits, with the maximum profit of $30.21 € / \mathrm{kWh}$. While there are echelon utilization scenarios for energy storage, only the renewable energy power station can achieve positive benefits. Its profit level is far lower than the power battery scheme. This is mainly due to the difference in performance requirements between the power battery and the energy storage battery. That is to say that the retired batteries of NEVs that were originally used as power batteries are more suitable to continue to be used as low-performance power batteries. If it is to be used as the energy storage battery, the processing cost of the battery will be much higher, making it difficult to make profits. Of course, the battery design of NEVs is only based on the requirement of the power system itself at present without considering the potential echelon utilization in the future, especially for energy storage scenarios [44-46]. Thus, if the performance requirements of the energy storage battery are properly considered at the beginning 
of the battery design, the evaluation results may be significantly different. This is also an important decision-making factor for relevant enterprises to consider seriously.

Generally speaking, E-Bike is the application scenario with the highest profit from echelon utilization at present. However, the demand for retired batteries of E-Bike is limited, and urban regulatory policies are being tightened continuously. It is expected that the follow-up market scale will not be able to grow significantly and cannot accommodate the increasing number of retired power batteries of NEVs. At the same time, microelectric vehicles, commonly known as low-speed electric vehicles, have not been officially recognized by the Chinese government. Therefore, the electric-special vehicle may be the most feasible entry point for automobile enterprises to try to use battery echelons in the near future. In the long run, although the benefits of energy storage scenarios such as renewable energy power stations are relatively low, there is a very broad further market. Especially, China has made the strategic goal of building a low-carbon society and low-carbon industry. China needs a large number of energy storage batteries, which will play an important role in reducing clean power waste and optimizing the balance of power grid urgently. In this sense, the echelon utilization of energy storage scenarios may have more market potential in the future. [37].

\section{Research on the Recycling Value of Power Battery}

The recycling of power battery mainly includes the process of dismantling, crushing, repairing, and smelting. Its purpose is to realize the recycling of resources on the basis of eliminating environmental pollution and potential safety hazards [47]. The recovery and utilization of battery materials, especially metals such as lithium, nickel, and cobalt, could also generate certain economic benefits [48]. Considering that $\mathrm{Ni}_{0.5} \mathrm{Co}_{0.2} \mathrm{Mn}_{0.3}$ (NCM523) lithium battery is the most recently retired TL battery, this paper analyzes the recycling value of LIP power battery and TL battery NCM523.

In this paper, the economic benefit evaluation model of power battery recycling is built. It can be seen in Figure 8 for details.

\begin{tabular}{|c|c|c|c|c|c|}
\hline Link & Battery purchase & Transportation & $\begin{array}{c}\text { Battery dismantling } \\
\text { and recycling }\end{array}$ & Transportation & $\begin{array}{c}\text { Sale revenue of } \\
\text { resources }\end{array}$ \\
\hline Cost & $\begin{array}{c}\text { Purchase cost of } \\
\text { retired batteries }\end{array}$ & $\begin{array}{c}\text { Batteries } \\
\text { transportation cost }\end{array}$ & $\begin{array}{c}\text { Battery dismantling } \\
\text { and recycling cost }\end{array}$ & $\begin{array}{c}\text { Batteries } \\
\text { transportation cost }\end{array}$ & \\
\hline Income & & & & $\begin{array}{c}\text { Sales revenue of battery } \\
\text { recycling resources }\end{array}$ \\
\hline
\end{tabular}

Figure 8. Block diagram of the economic benefit evaluation model for battery recycling.

As shown in Figure 8, the cost of the recycling process mainly includes purchase, transportation, and dismantling cost of the retired batteries (including the two situations of direct retirement from the NEVs or retirement after echelon utilization), and the revenue mainly comes from the sale of the recovered materials [42]. Therefore, the economic benefits of recycling can be calculated by Equation (11):

$$
P_{r}=S R_{r}-C_{p 2}-C_{d r}-C_{t r}
$$

where the $P_{r}$ is the profit of recycling; $\mathrm{SR}_{r}$ represents the sales revenue of battery recycling resources; $C_{p 2}$ indicates the battery purchase cost; $C_{d r}$ represents battery dismantling and recovery cost; $C_{t r}$ indicates battery transportation cost. 
The sales revenue of battery recycling resources is mainly from the sales of lithium, cobalt, nickel, and other metal materials. It is assumed that all recovered metal materials can be fully reused. The calculation equation is as follows:

$$
C_{p 2}=\sum_{j}\left(P_{j} \cdot Q_{j} \cdot R R_{j}\right)
$$

where the $P_{j}$ is the price of the metal $j$, note that the price of various metals in 2018 is taken in this paper, as shown in Table 5 [10]; $Q_{j}$ represents the recyclable amount of the metal $j$ in retired batteries per $\mathrm{kWh} ; R R_{j}$ represents the recovery rate of the metal $j$, which is determined by the current recovery technology, as shown in Table 5 [10].

Table 5. Average market price and recovery rate of raw metal materials for power battery (2018).

\begin{tabular}{cccccc}
\hline Element Type & Lithium & Cobalt & Nickel & Manganese & Aluminum \\
\hline Average price $(€ / \mathrm{t})$ & 117,828 & 771,769 & 3600 & 1858 & 1845 \\
Recovery rate & $85 \%$ & $98 \%$ & $98 \%$ & $98 \%$ & $90 \%$ \\
\hline
\end{tabular}

Retired battery purchase cost: the initial purchase cost of the retired LIP battery is the same as that of the echelon utilization analysis, referring to the average industry price. As for the battery after echelon utilization (LIP battery), this paper assumes that the repurchase cost will be greatly reduced when recycling due to the large performance degradation. This paper takes the average price of the industry, about $3.87 € / \mathrm{kWh}$ [10]. However, for the TL battery with high energy density and metal resources, this paper assumes that the purchase cost of TL battery to LIP battery is proportional to the price ratio of the new batteries.

Cost of battery dismantling and recycling: the wet recovery method is widely used in the industry at present. This method extracts the required metal materials after soaking the cathode materials with chemical reagents. According to the current technical level, the cost of dismantling and recovering the LIP battery is about $7.55 \mathrm{E} / \mathrm{kWh}$, and the cost of recovery of the TL battery (NCM523) is about $12.58 € / \mathrm{kWh}[15]$.

Battery transportation cost: only intercity transportation is considered because dismantling and recycling enterprises would be near the power battery recovery areas generally. At the same time, its calculation method is the same as that in the echelon utilization model.

Based on the above model, the TL (NCM523) battery and the LIP battery are calculated. Among them, the TL (NCM523) battery is analyzed in terms of the abovementioned mode I (recycling directly after retirement), while the LIP battery is analyzed in terms of mode I and mode II (recycling after echelon utilization). The evaluation results of battery recycling are shown in Figure 9.

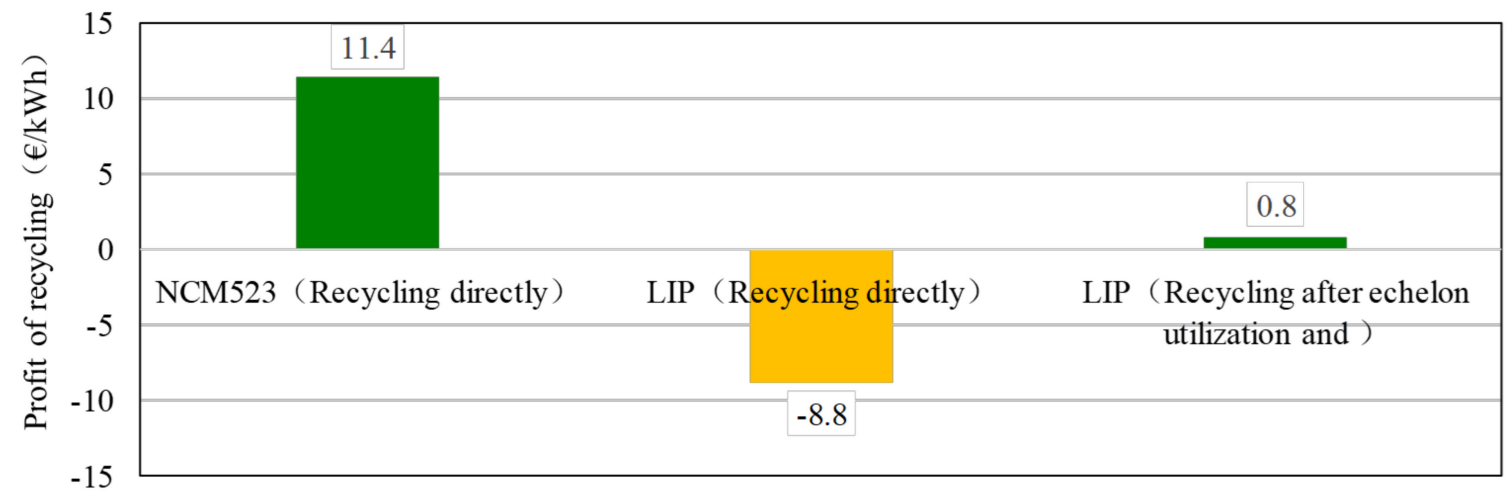

Figure 9. Analysis of the economic benefits of recycling of the retired power battery. 
It can be seen from the figure that the TL battery (NCM523) has a high recycling income with a profit of about $11.41 € / \mathrm{kWh}$, which is mainly due to the large number of metal materials contained in the TL (NCM523) battery. However, due to the low value of reusable materials, if the LIP battery is recycled directly, it will cause a loss of $8.77 € / \mathrm{kWh}$. If the government begins to implement the mandatory recycling of retired power batteries, the loss will become an additional cost for enterprises. However, if the LIP battery is first used in echelon utilization and then disassembled for recycling, the profit of $0.79 € / \mathrm{kWh}$ from battery recycling can be realized. It is equivalent to reduce the use cost of LIP battery when recycling after echelon utilization.

\section{Overall Analysis of Retired Power Battery Reusing}

The following is an analysis of the overall economic benefits of the power battery reusing of NEVs. Meanwhile, a comparative analysis of the use economy of TL (NCM523) battery and LIP battery from the perspective of industrial concerns is conducted.

According to the industry average data, the selling prices of TL battery (NCM523) and LIP battery are $155 € / \mathrm{kWh}$ and $129 € / \mathrm{kWh}$ at present, respectively [34]. Combined with the above economic benefit evaluation results of echelon utilization and recycling, the use costs of two power batteries in NEVs can be calculated. Note that the use cost represents that enterprises need to pay for the use of the power battery. The specific calculation equation is as follows:

$$
P_{u}=P_{p}-P_{c}-P_{r}
$$

where the $P_{u}$ indicates the cost of using the battery; $P_{p}$ represents the original battery price; $P_{c}$ indicates the profit of the echelon utilization of retired power battery. Note that the profit is zero if echelon utilization is not carried out; $P_{r}$ represents the profit of recycling of retired power batteries.

The specific calculation results are shown in Figure 10. For the LIP battery, if it is recycled directly, its cost will increase. However, if the echelon utilization with the appropriate scenario is implemented (Figure 10 shows the minimum benefit in the low-performance power battery scenario, which is the electric special vehicle scenario), the use cost of the LIP battery will be significantly reduced to $105.3 € / \mathrm{kWh}$. Thus, the best reusing mode is to carry out primary echelon utilization and then recycle for the LIP power battery.

The list in Figure 10 shows the change of the use cost of the TL (NCM523) battery and the LIP battery in different reusing modes relative to the original price of the TL (NCM523) battery. It can be found that the use cost of the LIP battery recycling directly is $5.5 € / \mathrm{kWh}$, or $3.9 \%$ lower than that of the TL (NCM523) battery. Nevertheless, it weakens the cost advantage of the original LIP battery compared with the TL (NCM523) battery. Instead, the use cost of the LIP battery after echelon utilization and recycling could be $38.2 € / \mathrm{kWh}$ lower than the TL (NCM523) battery, or about $27 \%$. There is a $23.1 \%$ cost reduction potential for the echelon utilization of the LIP battery if regulations mandate battery recycling. This will improve the cost competitiveness of the LIP battery further. However, there is no feasible technical scheme for the echelon utilization of the TL battery at present. If we can make a breakthrough in this aspect in the future, it may improve the cost-effectiveness of the TL battery significantly.

According to the technological roadmap for energy-saving and new energy vehicles in China, the industry-wide unit cost of a battery pack will be reduced to $104 € / \mathrm{kWh}$ in 2025 and $73 € / \mathrm{kWh}$ in 2030 [9]. In this paper, we assume that the price of the LIP battery is the same as the technological roadmap. The price of the TL battery is assumed that the degree of reduction is the same as that of LIP battery, as the technological roadmap suggested. Moreover, there is no available cost data for the battery reusing technological progress. The dismantling and recycling techniques for recycling and detection and regrouping techniques for echelon utilization are assumed to keep constant. The transportation cost in reusing is assumed to be constant. The other costs are assumed to be proportional to the battery prices. 


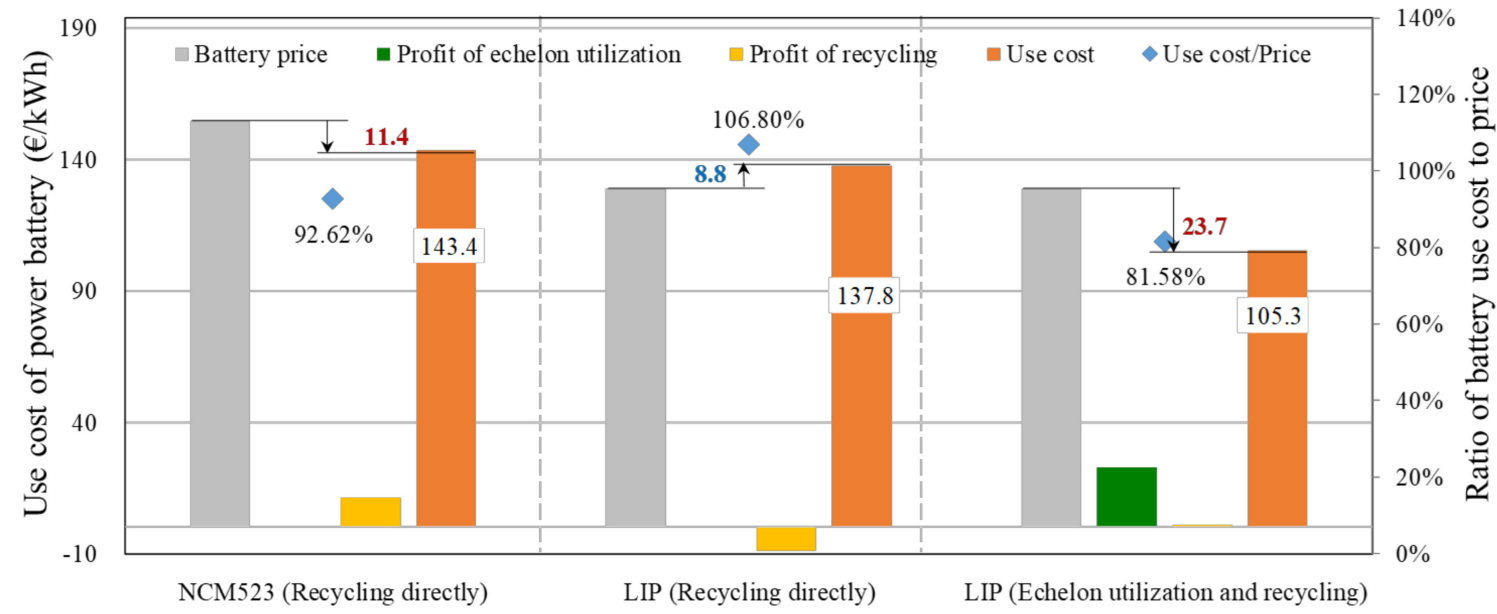

\begin{tabular}{|c|c|c|c|c|}
\hline $\begin{array}{l}\text { Relative cost change } \\
\text { Schemes }\end{array}$ & Battery price & Echelon utilization & Recycling & Use cost \\
\hline NCM523(Recycling directly) & $100 \%$ & $0 \%$ & $7.37 \%$ & $92.63 \%$ \\
\hline LIP (Recycling directly) & $83.33 \%$ & $0 \%$ & $-5.67 \%$ & $0.89 \%$ \\
\hline $\begin{array}{l}\text { LIP (Echelon utilization and } \\
\text { recycling) }\end{array}$ & $83.33 \%$ & $14.85 \%$ & $0.50 \%$ & $67.98 \%$ \\
\hline
\end{tabular}

Figure 10. Comparison of use costs of NCM523 battery and LIP battery.

Therefore, according to the abovementioned assumptions, the use costs of the TL and LIP batteries could be predicted, as shown in Figure 11. It could be seen that the use costs of power batteries are decreased with the battery prices decreased regardless of the varieties of batteries. The TL battery could reduce to $89.1 € / \mathrm{kWh}$ in 2030 by recycling directly. The LIP battery could reduce to $72.5 € / \mathrm{kWh}$ in 2030 by recycling after echelon utilization. It should be noted that the extent of reduction of the use cost of TL batteries is more than that of the LIP battery due to the assumption that the reusing technical progress cost is constant. In fact, the cost of recycling technology reduces with the development of technology gradually, so the use cost of the LIP battery will be relatively lower than the TL battery.

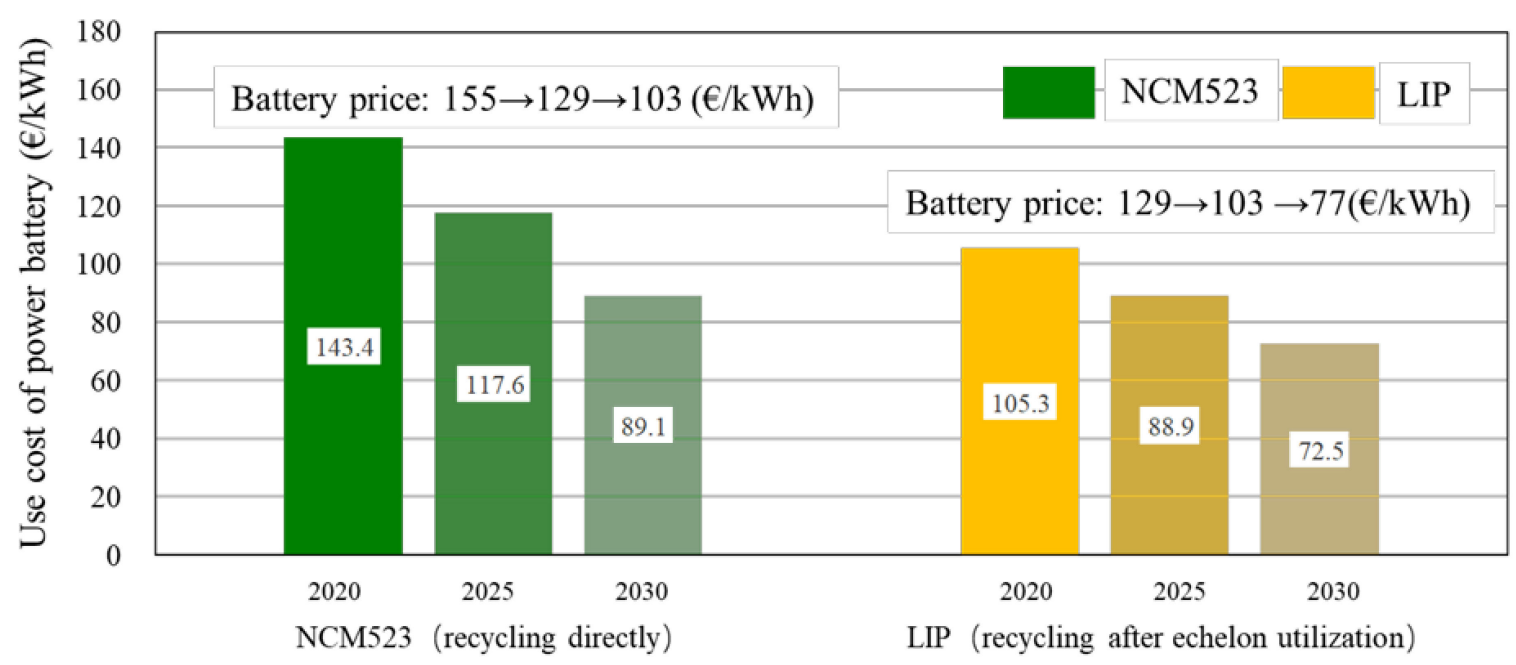

Figure 11. The use costs of different power batteries with the battery prices decreased.

\section{Policy Suggestion}

Based on the research and evaluation of the critical issues in the reusing of retired power batteries, this paper proposes some policy suggestions for the government and enterprises. First, China is about to usher in the peak period of retired power batteries, and mandatory recycling is imminent by the 
government. The relevant enterprises should make arrangements and preparations in advance so as to meet the regulations. Second, while multi-level echelon utilization is practical in theory, it is not economically feasible at present. In the industrial practice, more attention should be paid to the first level of echelon utilization in the future. At the same time, the two-level echelon utilization scheme should be considered properly according to the urgency of the scene demand. Third, the feasibility and profit of the echelon utilization are highly dependent on the requirements of battery performance at each utilization stage, implying the importance of performance matching. Thus, special consideration should be given to the huge market potential of energy storage in China. Besides, the future design of NEV power batteries may need to give due consideration to the performance requirements of the energy storage battery. Finally, the TL battery can only be recycled directly, while the LIP battery is suitable for echelon utilization and recycling at present. This would further improve the cost advantage of the lithium iron phosphate battery. Therefore, automotive enterprises should manage the power battery from the perspective of the whole life cycle to achieve the lowest use cost.

Looking forward to the future, it is imperative to reuse the retired power battery of NEVs. With the decrease of the battery price and the maturity of the reusing technology, the revenue from the reuse of retired power battery will be further improved. The government and related enterprises should increase the research of battery materials and recycling technology so as to reduce the price of batteries and the cost of recycling. Besides, the use cost of the LIP after reusing is lower than TL batteries; the enterprise should make it a key factor in determining the power battery technology route in the future.

\section{Conclusions and Limitation}

This paper aims to reveal the critical issues for power battery reusing of NEVs in China by the strategic value analysis and building the economic benefit model. Based on the results and discussion, some conclusions could be drawn:

1. Power battery reusing has three aspects strategic values such as protecting the environment and eliminating potential safety problems of retired power batteries, realizing resource recovery and reducing the risk of battery material supply and reducing the use cost of power battery and then improving the competitiveness of NEVs.

2. The echelon utilization of retired LIP batteries would be profitable if the relevant industry chain could be coordinated. The primary echelon utilization of retired LIP could obtain the maximum profit in the E-Bike application scenario of $30.21 € / \mathrm{kWh}$. While the profits of two-level echelon utilization are relatively lower. Thus, more attention should be paid to the first level echelon utilization in the future.

3. The TL battery (NCM523) has a high recycling income with a profit of about $11.41 € / \mathrm{kWh}$, while the LIP battery is recycled directly, causing a loss of $8.77 € / \mathrm{kWh}$ for LIP recycling directly. Instead, if the LIP battery is first used in echelon utilization and then disassembled for recycling, the profit of $0.79 € / \mathrm{kWh}$ from battery recycling can be realized.

4. The use cost of the LIP battery after echelon utilization and recycling could be $38.2 € / \mathrm{kWh}$ lower than the TL (NCM523) battery recycling directly. This would further improve the cost advantage of the lithium iron phosphate battery. Hence, the best reusing mode for the TL battery is recycling directly, while the LIP battery is suitable for echelon utilization and recycling at present.

5. The use costs of power batteries are decreased, with the battery prices decreased regardless of the varieties of batteries. The TL battery could reduce to $89.1 € / \mathrm{kWh}$ in 2030 by recycling directly. The LIP battery could reduce to $72.5 € / \mathrm{kWh}$ in 2030 by recycling after echelon utilization.

However, it should be noted that this study is based on the ideal assumption that every link of recycling has been fully coordinated. Meanwhile, the model assumes the cost of dismantling and regrouping at the first-level and second-level echelon utilization is the same, while the cost of dismantling and regrouping at the second-level echelon utilization is higher. Therefore, we will refine 
the model by taking these limitations into consideration and improve the accuracy of the model in future work.

Author Contributions: Conceptualization, Z.L. and F.Z.; methodology, Z.L. and X.L.; validation, Z.L., X.L.; formal analysis, X.L.; investigation, X.L.; resources, X.L.; data curation, X.L.; writing-original draft preparation, Z.L. and X.L.; writing-review and editing, H.H. and Z.L.; visualization, X.L.; supervision, A.A.A. and H.B.; project administration, F.Z. and Z.L.; funding acquisition, Z.L., A.A.A. and H.B. All authors have read and agreed to the published version of the manuscript.

Funding: This study is supported by the National Natural Science Foundation of China (U1764265) and the Chinese Academy of Engineering (2019-XZ-55-01-01).

Acknowledgments: The authors would like to thank Zaidan Chen for her help collect the industrial data of power batteries. Additionally, the authors would like to thank the anonymous reviewers for their reviews and comments.

Conflicts of Interest: The authors declare no conflict of interest.

\section{Abbreviations}

$\begin{array}{ll}\text { NEV } & \text { New Energy Vehicle } \\ \text { ICEV } & \text { Internal Combustion Engine Vehicles } \\ \text { MEV } & \text { Micro Electric Vehicle } \\ \text { ESV } & \text { Electric Special Vehicle } \\ \text { E-Bike } & \text { Electric Bike } \\ \text { CBS } & \text { Communication Base Station } \\ \text { REPS } & \text { Renewable Energy Power Station } \\ \text { PMG } & \text { Parallel Micro-grid } \\ \text { LIP } & \text { Lithium Iron Phosphate batteries } \\ \text { TL } & \text { Ternary Lithium battery } \\ \text { LA } & \text { Lead-acid battery } \\ \text { DOD } & \text { Depth of Discharge }_{\text {NCM523 }} \mathrm{Ni}_{0.5} \mathrm{Co}_{0.2} \mathrm{Mn}_{0.3} \text { ternary lithium battery } \\ \text { NREL } & \mathrm{National} \mathrm{Renewable} \mathrm{Energy} \mathrm{Laboratory}\end{array}$

\section{References}

1. Chen, K.; Zhao, F.; Hao, H.; Liu, Z. Synergistic impacts of China's subsidy policy and new energy vehicle credit regulation on the technological development of battery electric vehicles. Energies 2018, 11, 3193. [CrossRef]

2. Hao, H.; Cheng, X.; Liu, Z.; Zhao, F. China's traction battery technology roadmap: Targets, impacts and concerns. Energy Policy 2017, 108, 355-358. [CrossRef]

3. Liu, F.; Zhao, F.; Liu, Z.; Hao, H. China's electric vehicle deployment: Energy and greenhouse gas emission impacts. Energies 2018, 11, 3353. [CrossRef]

4. CAAM. China's Automotive Industry Satus in 2019; China Association of Automobile Manufacturers: Beijing, China, 2020. [CrossRef]

5. China Battery Enterprise Alliance. Available online: http://pba.cbea.com/ (accessed on 15 January 2020).

6. Tang, Y.; Zhang, Q.; Li, Y.; Wang, G.; Li, Y. Recycling mechanisms and policy suggestions for spent electric vehicles' power battery-A case of Beijing. J. Clean. Prod. 2018, 186, 388-406. [CrossRef]

7. Huang, B.; Pan, Z.; Su, X.; An, L. Recycling of lithium-ion batteries: Recent advances and perspectives. J. Power Sources 2018, 399, 274-286. [CrossRef]

8. MIIT. Policy Document. Available online: http://www.miit.gov.cn/n1146295/n1652858/index.html (accessed on 16 December 2019).

9. SAE-China. Technology Roadmap for Energy-Saving and New Energy Vehicles; Chinese Society of Automotive Engineers: Beijing, China, 2016. [CrossRef]

10. Orient Securities. Power Battery Recycling. Available online: http://www.nxny.com/stype_54_p153/ (accessed on 23 October 2018).

11. Mayyas, A.; Steward, D.; Mann, M. The case for recycling: Overview and challenges in the material supply chain for automotive li-ion batteries. Sustain. Mater. Technol. 2019, 19. [CrossRef] 
12. Sonoc, A.; Jeswiet, J.; Soo, V.K. Opportunities to improve recycling of automotive lithium ion batteries. Procedia Cirp 2015, 29, 752-757. [CrossRef]

13. Pagliaro, M.; Meneguzzo, F. Lithium battery reusing and recycling: A circular economy insight. Heliyon 2019, 5. [CrossRef]

14. Wang, T.; Song, D.; Li, G.; Huang, J.; Zhu, H.; He, W. Recycling Potential for Waste Electric Vehicle Lithium-ion Batteries in China. Available online: https://pdfs.semanticscholar.org (accessed on 10 October 2018).

15. China Automotive Technology \& Research Center. China New Energy Vehicle Power Battery Recycling Industry Development Report; Publishing House of Electronics Industry: Beijing, China, 2019. [CrossRef]

16. Ahmadi, L.; Yip, A.; Fowler, M.; Young, S.B.; Fraser, R.A. Environmental feasibility of re-use of electric vehicle batteries. Sustain. Energy Technol. Assess. 2014, 6, 64-74. [CrossRef]

17. Steward, D.M.; Mayyas, A.T.; Mann, M.K. Economics and challenges of Li-ion battery recycling from end-of-life vehicles. Procedia Manuf. 2019, 33. [CrossRef]

18. Unterreiner, L.; Jülch, V.; Reith, S. Recycling of battery technologies-Ecological impact analysis using life cycle assessment (LCA). Energy Procedia 2016, 99, 229-234. [CrossRef]

19. Liu, Z.; Hao, H.; Cheng, X.; Zhao, F. Critical issues of energy efficient and new energy vehicles development in China. Energy Policy 2018, 115, 92-97. [CrossRef]

20. Reinhardt, R.; Christodoulou, I.; Gassó-Domingo, S.; García, B.A. Towards sustainable business models for electric vehicle battery second use: A critical review. J. Environ. Manag. 2019, 245, 432-446. [CrossRef] [PubMed]

21. Qiao, Q.; Zhao, F.; Liu, Z.; Hao, H. Recycling-based reduction of energy consumption and carbon emission of China's electric vehicles: Overview and policy analysis. WCX World Cong. Exp. 2018, 1. [CrossRef]

22. Qiao, Q.; Zhao, F.; Liu, Z.; Hao, H. Electric vehicle recycling in China: Economic and environmental benefits. Resour. Conserv. Recycl. 2019, 140, 45-53. [CrossRef]

23. Casals, L.C.; Amante Garcia, B.; Canal, C. Second life batteries lifespan: Rest of useful life and environmental analysis. J. Environ. Manag. 2019, 232, 354-363. [CrossRef]

24. Madlener, R.; Kirmas, A. Economic viability of second use electric vehicle batteries for energy storage in residential applications. Energy Procedia 2017, 105, 3806-3815. [CrossRef]

25. Cusenza, M.A.; Guarino, F.; Longo, S.; Mistretta, M.; Cellura, M. Reuse of electric vehicle batteries in buildings: An integrated load match analysis and life cycle assessment approach. Energy Build. 2019, 186, 339-354. [CrossRef]

26. Diouf, B.; Pode, R.; Osei, R. Recycling mobile phone batteries for lighting. Renew. Energy 2015, 78, 509-515. [CrossRef]

27. Neubauer, J.; Pesaran, A. The ability of battery second use strategies to impact plug-in electric vehicle prices and serve utility energy storage applications. J. Power Sources 2011, 196, 10351-10358. [CrossRef]

28. Song, Z.; Feng, S.; Zhang, L.; Hu, Z.; Hu, X.; Yao, R. Economy analysis of second-life battery in wind power systems considering battery degradation in dynamic processes: Real case scenarios. Appl. Energy 2019, 251. [CrossRef]

29. Boyden, A.; Soo, V.K.; Doolan, M. The environmental impacts of recycling portable lithium-ion batteries. Procedia Cirp 2016, 48, 188-193. [CrossRef]

30. Harper, G.; Sommerville, R.; Kendrick, E.; Driscoll, L.; Slater, P.; Stolkin, R.; Walton, A.; Christensen, P.; Heidrich, O.; Lambert, S. Recycling lithium-ion batteries from electric vehicles. Nature 2019, 575, 75-86. [CrossRef] [PubMed]

31. Martinez-Laserna, E.; Gandiaga, I.; Sarasketa-Zabala, E.; Badeda, J.; Stroe, D.I.; Swierczynski, M.; Goikoetxea, A. Battery second life: Hype, hope or reality? A critical review of the state of the art. Renew. Sustain. Energy Rev. 2018, 93, 701-718. [CrossRef]

32. Guo, Y.; Luo, M.; Zou, J.; Liu, Y.; Kang, J. Temperature Characteristics of Ternary-Material Lithium-Ion Battery for Vehicle Applications; 0148-7191; SAE Technical Paper: Warrendale, PA, USA, 2016.

33. Tredeau, F.P.; Salameh, Z.M. Evaluation of lithium iron phosphate batteries for electric vehicles application. In Proceedings of the 2009 IEEE Vehicle Power and Propulsion Conference, Dearborn, MI, USA, 7-10 September 2009; pp. 1266-1270.

34. China Automotive Technology \& Research Center. Annual Report on the Development of New Energy Vehicle Power Battery Industry in China; Social Sciences Academic Press: Beijing, China, 2019. 
35. Gilbert, J.A.; Bareño, J.; Spila, T.; Trask, S.E.; Miller, D.J.; Polzin, B.J.; Jansen, A.N.; Abraham, D.P. Cycling behavior of NCM523/graphite lithium-ion cells in the 3-4.4 V range: Diagnostic studies of full cells and harvested electrodes. J. Electrochem. Soc. 2017, 164, A6054-A6065. [CrossRef]

36. Wang, W.; Wu, Y. An overview of recycling and treatment of spent LiFePO 4 batteries in China. Resour. Conserv. Recycl. 2017, 127, 233-243. [CrossRef]

37. Liu, J. Second use potential of retired EV batteries in power system and associated cost analysis. Energy Storage Sci. Technol. 2017, 6, 243-249.

38. Li, M.; Yang, J.; Liang, S.; Hou, H.; Hu, J.; Liu, B.; Kumar, R.V. Review on clean recovery of discarded/spent lead-acid battery and trends of recycled products. J. Power Sources 2019, 436. [CrossRef]

39. Yang, Y.; Zhu, W.; Xie, C.; Shi, Y.; Liu, F.; Li, W.; Tang, Z. A layered bidirectional active equalization method for retired power lithium-ion batteries for energy storage applications. Energies 2020, 13, 832. [CrossRef]

40. Liu, X.; Deng, X.; He, Y.; Zheng, X.; Zeng, G. A dynamic state-of-charge estimation method for electric vehicle lithium-ion batteries. Energies 2019, 13, 121. [CrossRef]

41. Schuster, F.S.; Bach, T.; Fleder, E. Nonlinear aging characteristics of lithium-ion cells under different operational conditions. J. Energy Storage 2015, 1, 44-53. [CrossRef]

42. Li, L.; Dababneh, F.; Zhao, J. Cost-effective supply chain for electric vehicle battery remanufacturing. Appl. Energy 2018, 226, 277-286. [CrossRef]

43. Newbauer, J.; Pesaran, A. NREL's PHEV/EV Li-Ion Battery Secondary-Use Project; National Renewable Energy Lab.(NREL): Golden, CO, USA, 2010.

44. Manzetti, S.; Mariasiu, F. Electric vehicle battery technologies: From present state to future systems. Renew. Sustain. Energy Rev. 2015, 51, 1004-1012. [CrossRef]

45. Baron, C.; Al-Sumaiti, A.S.; Rivera, S. Impact of energy storage useful life on intelligent microgrid scheduling. Energies 2020, 13, 957. [CrossRef]

46. Gaines, L. The future of automotive lithium-ion battery recycling: Charting a sustainable course. Sustain. Mater. Technol. 2014, 1-2, 2-7. [CrossRef]

47. Ordoñez, J.; Gago, E.J.; Girard, A. Processes and technologies for the recycling and recovery of spent lithium-ion batteries. Renew. Sustain. Energy Rev. 2016, 60, 195-205. [CrossRef]

48. Wang, X.; Gaustad, G.; Babbitt, C.W.; Richa, K. Economies of scale for future lithium-ion battery recycling infrastructure. Resour. Conserv. Recycl. 2014, 83, 53-62. [CrossRef] 